\title{
Transdisciplinary Team in Rehabilitation of Unconscious Brain-Damaged Persons: Grounds and Practice
}

\author{
Olga Maksakova ${ }^{1}$, Ludmila Zhavoronkova ${ }^{2}$ \\ ${ }^{1}$ N.N.Burdenko National Medical Research Center of Neurosurgery, Moscow, Russia \\ ${ }^{2}$ Institute of Higher Nervous Activity and Neurophysiology, Russian Academy of Sciences, Moscow, Russian \\ Email: *omaksakova46@gmail.com
}

How to cite this paper: Maksakova, O., and Zhavoronkova, L. (2020) Transdisciplinary Team in Rehabilitation of Unconscious Brain-Damaged Persons: Grounds and Practice. Journal of Behavioral and Brain Science, 10, 323-343.

https://doi.org/10.4236/jbbs.2020.108021

Received: June 24, 2020

Accepted: August 10, 2020

Published: August 13, 2020

Copyright $\odot 2020$ by author(s) and Scientific Research Publishing Inc. This work is licensed under the Creative Commons Attribution International License (CC BY 4.0).

http://creativecommons.org/licenses/by/4.0/

(c) (i) Open Access

\begin{abstract}
The main features of early rehabilitation after severe brain damage are discussed in the article. The most important component for the entire rehabilitation process and the subsequent life of the patient is considered restoration of consciousness. Team seems to be a key factor in regaining consciousness along with the restoration of vital functions, movement, cognition, and behavior in these patients. The basic working principle is feedback to any minimal movement, or vegetative signal of a patient, beyond specific professional targets. A network of feedbacks with a patient and between professionals, that is, free flow of information, can be built only through work in a transdisciplinary team mode. The net of feedbacks with the patient and inter-professional ones builds up the team as Non-linear Complex System. Characteristics of "Team-Patient" system status are energy, entropy, and complexity. Teamwork techniques are individualized for resulting optimization of system condition. Increase of complexity is a powerful tool for propulsion of recovery process. Then consciousness may appear as a result of system self-organization. The article reflects the authors' view on interdisciplinary studies of the phenomenon of consciousness through its impairment and recovery. It focuses on the work of the "proper rehabilitation team", the mechanisms of its action and methods for researching the occurring phenomena.
\end{abstract}

\section{Keywords}

Severe Brain Damage, Unconsciousness, Neurorehabilitation, Team as Complex System, Mind-Body Problem 


\section{Introduction}

Field of human factors is important to ensure that neurorehabiltation (NR) technology is indeed functional, process-oriented, effective, as well as antropocentric. The intention of this paper is to propose an innovative cooperative working culture for NR based on more than 25 years of our own clinical experience, the interdisciplinary literature on various organizational theories, on non-linear theories and methods with their practical application in medicine and psychology, as well, as some concepts of philosophy of consciousness.

The medical community has recently come to understanding of the relation between outcomes of severe brain injuries and quality of rehabilitation [1] [2]. This recognition has led to organizational and financial efforts aimed at creation of rehabilitation network. Neurosurgeons and intensive care physicians typically focus on early physical rehabilitation of post-coma patients after brain catastrophes. Usually this means a set of drugs, passive exercises, and exposure to physical factors in long-term impairment of consciousness. This viewpoint is also rooted among most neurorehabilitologists working in intensive rehabilitation.

Specialists' concern about the level of consciousness manifests at all post-coma stages. Certainly, during the most acute period coma reflects the life-threatening brain condition that requires urgent surgical and resuscitation measures. However, in less critical phase with restoration of self-control of vital functions, clinicians' desire to see at least some glimpses of consciousness in the patient becomes somewhat irrational. In contrast to family members for whom their case is unique, physicians are aware of how often the patient's behavior appearing makes the family life painful for years. Need for patient's "consciousness" during the rehabilitation is a completely rational aspect of the work: active patient's involvement is the most important factor in achieving the best possible result in the least amount of time [3].

When considering a number of applied tasks related to the restoration of consciousness, first, it is necessary to determine terminologically.

There are several discourses of consciousness:

1) philosophical theory of consciousness, with equal cogency proving diametrically opposite views;

2) clinical classifications;

3) brain's locality and neurophysiological features. Most information is received by natural models: sleep, anesthesia, effect of certain drugs, and other;

4) neuroimaging evidences of consciousness in the absence of behavioral signs. This approach overlaps with the previous position, but because of fundamental differences in technical capabilities, their languages differ greatly;

5) instrumental methods aimed at restoring "awakening of mind" after severe brain diseases (deep brain stimulation, transcranial magnetic stimulation, ultrasound stimulation). 
In recent years, mutual interest among neuroscientists and philosophers of consciousness steadily has grown. Philosophers have used the facts obtained neuroscience as proof of their own interpretations of Mind-Brain problem.

\subsection{Some Philosophical Concepts of Consciousness}

In last decade of XIX and two decades of XX century it was considered obvious in psychology that conscious experience is a basic phenomenon [4]. Studies and even mentioning consciousness were largely restrained during behaviorism power (first half of the 20th century). Together with the return of "mind" concept (second half of the century), mentioning consciousness gradually returned into the cognitive science, mainly in connection with investigations of attention and short-term memory. It was assumed that consciousness is nothing more than information processing, thereby all phenomenological experience was cut off. It was only in the early 1990s they recognized that methods used to study consciousness affected the perception of consciousness itself. Scientific interest has arisen primarily owing to philosophers [5] [6] [7].

Perhaps the process of integration to solve the problem was launched due to accumulation of technologies. Since the 2000s, it has become especially productive. At numerous interdisciplinary meetings physicists, neurologists, spiritual practitioners, artificial intelligence experts, mathematicians, philosophers, psychologists, anthropologists, therapists, artists tried to reach a common understanding of Mind-Body problem with their own discourses. D. Chalmers [8] [9] who nowadays is considered one of the deans in the field blew the debate. $\mathrm{He}$ was the first who distinguished between "easy problems" and "hard problem of consciousness". Indeed, why is the brainwork accompanied by subjective experience? Consciousness is not reducible to cerebral processes because there is also elusive qualia corresponding to unique contents that do not arise from biological concepts. Russian philosopher Vadim Vasil'ev [10] believes that the following statement is most accurate: “... mental states are ontological preconditions for implementing physical causality and even the very existence of the physical properties. The existence of mental states associated with certain physical systems gives these systems an opportunity to take into account their own individual story in their behavior". This forced the representatives of neuroscience to avoid simplifications, who have also understood the incompleteness of looking for consciousness in brain depths [11].

Since 1980-90s, Rodger Penrose, mathematician, has been trying to develop a general theory of consciousness [12]. He put forward the synergic physical concept, in which the leading role belongs to self-organization processes occurring at quantum level. Consciousness may manifest itself at different levels of human existence: organismic, personal and social [13]. Therefore, when organizing an experiment (be it mental, natural, or laboratory), the researcher must determine exactly what level the methodology used (artificial intelligence, neuroscience, psychology, etc.) is addressed to (brain circuits, neuronal correlates of consciousness, sets of higher mental functions, behavior). 
Artificial intelligence studies greatly expanded the capabilities of information technologies but did not bring modeling of consciousness. Meanwhile, due to this branch an integrated database of knowledge has been developed with the next step to information theories [14]. Giulio Tononi [15] argues that something "will have a form of 'consciousness' if the information contained within the structure is sufficiently 'integrated,' and so the whole is more than the sum of its parts. Because it applies to all structures (not just the human brain) Integrated Information Theory shares panpsychism point of view that physical matter has innate conscious experience".

Every scientific approach reduces some specific features of the object to create a model. Researchers in neurosciences usually choose reductionism, which reduces consciousness to separate function [16]. Yet physicalist Dennet continues to resist the "hard problem" of consciousness stubbornly and logically [17].

\subsection{Objectified View of a Clinician}

Reduction is typical feature of clinical science [18], that is why, in clinical models, disorders of "consciousness" are always considered as a result of "substrate" damage. Keywords in papers focused on this subject demonstrate searching for an object, but not a concept (prognostic factors, neurophysiological mechanisms of disturbance, etc.). Classification approach typical to clinics appeared as early as in XIX century [19]. Clinical studies of consciousness were designed on a hierarchical basis; impairments of consciousness are associated with structural and functional brain destruction; injury severity, current states are extrapolated to predict the outcome.

Neurological paradigm places level of consciousness, cognitive, emotional and personality disorders on the same scale, assuming that mental recovery is linear. Options for selection of the leading symptoms of impaired consciousness often reflect capabilities of clinics, pragmatic goals, and area of expertise of a clinician.

For instance, here is a fragment of the scale defining the vegetative state (VS).

- No evidence of self-awareness or awareness of environment; the patient is not able to interact with others.

- No evidence of stable, reproducible, purposeful or spontaneous behavioral response to visual, auditory, tactile or noxious stimuli.

- No evidence of understanding and expression of speech.

Paradoxically definition of consciousness state is given through the lack of evidence. Nevertheless, the agreement on VS term led to agreement on other states. Thus, the medical community has accepted term "state of minimal consciousness" (SMC) and its criteria [20] [21]. They include the limited but clearly discernible evidence of self- or environment awareness in form of execution of simple instructions, gestural or verbal yes/no responses, distinct verbalization or purposeful behavior proportional to relevant external stimuli. 
Recently, in order to avoid ethical and methodological problems VS was qualified as Unresponsive wakefulness (UW) [22]. Thus for clinicians consciousness is a sum of patient's abilities to establish contact, respond to repetitive external stimuli with similar motor behavior, visible to an observer, and to communicate.

The higher is "level of contact" (various forms of interaction with world), the vaguer it is to define patient's state. Akinetic mutism, first described in 1940s [23] is well recognizable, although being continuum partially overlapping with SMC.

The higher a patient moves along the scale of consciousness, the less the agreement upon definitions is. The Russian scale of post-coma recovery [24] increases the number of stages of recovering consciousness through specification of various forms of behavior. Classifications narrow or broaden the list of attributes to split concepts of consciousness (arousal-awareness). Meanwhile, a good clinician wittingly or unwittingly would prefer the nonlinearity, focusing on a detailed story of the patient and reading both the conclusion and diaries in any case history.

\subsection{Brain Functions Approach}

Mostly suggests that orientation only on behavioral symptoms is the major drawback of clinical classifications of impaired consciousness. Functional magnetic resonance imaging (fMRI) has shown that in some patients for a long time clinically qualified as vegetative state, verbal and some other types of brain stimulation resulted in activation of the same brain areas as in healthy volonteers. From these researchers' viewpoint it proved the presence of consciousness [25]. However, neuroimaging formulas are not universal. In some cases with "active paradigms" no signs of cortical activation in conscious patients were revealed by fMRI. Additional doubts arise, as trend towards universality (evidence-based medicine) makes researchers to limit paradigms used. It's possible that those $90 \%$ of VS patients who were suggested to be unconscious by fMRI just had not received their special stimulus. The absence of cerebral response may be indicative of inappropriate intention, motivation, cognitive deficits, psychological defense, etc. It is noteworthy that Belgian Coma Science Group, leading in the field, gradually moves towards combining the active and the so-called passive paradigm. The introduction of passive paradigm required to methodology enrichment, for example, by use of nonlinear EEG analysis [26]. Combination of two or more methods certainly broadens our understanding of damaged brain's functioning, but makes little difference for a particular patient. Even access to the entire set of brain responses to random external and internal stimuli leaves unsolved problem of overcoming the barrier between a patient and the world. One looks for targets responsible for consciousness, whether it is a local area or a link of the functional chain [27]. Stimulating agents and methods for delivering them to affected area are varied, but conception remains unchanged: biochemi- 
cal factor (drugs), physical effect (electromagnetic and other fields), biological agent (stem cells, genetic engineering) should reach areas responsible for consciousness. However, thus far there are no conclusive studies devoted to treatment of consciousness disorders. We suggest that complexity and multi-level structure are fundamental obstacles.

\subsection{Regarding Rehabilitation Team}

What is the difference between rehabilitologist's view and patient examination with tools? In addition to immediate and long-term goals of treatment, rehabilitologist should daily focus on special features that are peculiar to this particular patient. The reality of clinic is dynamic, nonlinear, random and often unpredictable. Nonlinearity is the law rather than exception of developing process. This fact causes much strain, which continues for a long time. Only people able to deal with this uncertainty are efficient in rehabilitation process. Understanding the complexity of existence is a step toward self-organization and building of professional activities.

Past 30 years demand of team approach has established in rehabilitation practice. It was schematic and often reduced to elaboration of rehabilitation program and analysis of patient's dynamics at joint discussions, similar with traditional clinical ones. Very few experts of rehabilitation realized how to interact with patients and colleagues within the team [28]. Team composition and rehabilitation program were usually determined in accordance with a set of patient's functional deficits. With this approach, the matter of the teamwork disappears, and lost consciousness is regarded as one of cognitive deficits.

There are examples of process-oriented team arrangement in a delayed period of traumatic brain injury (TBI). Thus, B. Wilson with co-authors [29] described necessary steps to define the goals of gradual recovery processes, separating and achieving these goals. They generally correlate with common social skills. Rehabilitation at this stage is primarily a learning process (with an occupational therapist and a neuropsycologist as main figuers) implying linear intervention-outcome relationship.

Socio-adaptive representations are inadequate in early rehabilitation: it is unclear, who is "responsible" for restoring of consciousness, whose aims and actions should set the tone in an attempt to restore it. Yet, rehabilitation experience shows that recovery is faster if patient's activity is used, i.e. the patient is a participant rather than an object.

Kurt Lewin founded working team concept in 1950s: a group of people gathered to solve a specific task should develop. He proposed an estimating algorithm for a well-functioning group, found that team leaders must possess special skills, showed how effective group processes may develope. The main principles of team activities were formulated in 1970s. The standards of a high-quality team are well-known. Thus, an interdisciplinary team (IDT) is a small group of specialists with different skills, created and working within an organization accord- 
ing to special rules, united by common purpose, goals, which are implemented based on mutual responsibility. Team work is most efficient when its own internal rules and principles of the organization are balanced, which provides favorable conditions for self-development.

For a long time IDT work was analyzed mainly with semi-structured interviews and scales evaluating each team member's activity, openness to discussions, comfort of cooperation, etc. Researches in the field focused on creating a model that would be most effective in dealing with a limited class of problems. These models consider following parameters: input (team structure), process (teamwork) and output (results). Both individual performances related to activities of the team and common deficits (lack of trust between team members, inefficient interaction during discussions, unclear role distribution, defocusing a problem, poor time management, lack of coordination with the principles and objectives of the organization) should be evaluated.

Studies of medical teams were launched during 2000s. Despite limitations associated with the object features, huge progress was achieved. There is no doubt that teamwork in this area is also a process, in which participants interact and work together to achieve desired results.

Surgical and intensive care teams demonstrate the most compelling results of such research and training carried out at workplace and on simulators [30]. These groups operate in a complex and dynamic environment characterized by multi-component solutions with rapidly changing and uncertain situations, informational overload, rigid time constraints and severe consequences of errors. Recently the real scientific approach corresponding to the complex object with all its nonlinearity has appeared in this field [31].

Team practice in neurorehabilitation appeared in early 1990s: more patients have survived after severe cerebral damage; structures of functional disorders have become more complex, need for interdisciplinary contacts became apparent. Methods of evaluating and types of trainings designed for other medical teams were not acceptable because of object specificity and process temporality: neurorehabilitation "object" in some sense should to acquire subject's features. Regular IDT training courses for social workers were conducted by British medical management experts in Moscow. The key principles were adapted to domestic reality by B. Shapiro [32].

Since early 1980s, the authors of this article together with colleagues have had long experience in the field of emergent neurorehabilitation. In most cases, patients were in a prolonged unconscious state, and VS diagnosis was not a contraindication. The work aimed at establishing contact with patients with disorders of consciousness started in 1992. Some techniques of process-oriented psychotherapy [33] had become an integral part of this work. Since mid-1990s, with psychologists appearing in early rehabilitation, a form of work organization gained importance, and team approach began to evolve intuitively [34]. Team trend in Western neurorehabilitation appeared at about the same time, although 
one can found mentioning of rehabilitation team much earlier [35].

\subsection{Main Types of Teams in Medicine}

Now there are a lot of articles devoted to terminological clearness in team research, but only few relate to neurorehabilitation itself [36] [37].

Multidisciplinary team (MDT) utilises skills and experiences of clinicians from different disciplines: members work with the patient independently, corresponding to their disciplines with clearly defined roles. They follow individual plans and specific tasks. MDTs are hierarchical, with a clear leading role of the physician. MDT leader determines the plan and goals of treatment, prescribes actions of every team member like prescribing drugs. He changes treatment, receiving information from team members and assessing current conditions of patients in accordance with the protocol.

Interdisciplinary team (IDT) demonstrates a more integrated approach of working together towards collaboratively set goals. The relationship in this model is significantly closer with joint patient-history taking, assessment, diagnosis, and management with shared goal setting involving various clinicians, patient and their family. Members are aware of other objects (patient's problems) and rates of changes, but are strictly confined within professional frames. The collaboration is based on sharing information about the disease and treatment.

Transdisciplinary team is a result of the evolution of team approach. TDT model values the knowledge and skill of team members. Members of TDT share knowledge, skills, and responsibilities across traditional disciplinary boundaries in assessment, diagnosis, planning and implementation. TDT work involves a certain amount of boundary blurring between disciplines and implies cross-training and flexibility in accomplishing tasks. It occurs when clinicians provide rehabilitation to the patient as a "whole". Transdisciplinary practice already occurs informally in some rehabilitation services and provided efficiency through reduced duplication, fragmentation of care and clinical intervention. TDT work is characterized by autonomy, division of work tasks, flexible change of leadership, free information exchange, shared decision making at different time scales [37].

The multicenter studies have shown that IDT rehabilitation is more efficient than MDT one. This means that a coordinated, horizontal management is preferred to vertical one. Team activities are usually analyzed according to skills and relations that form a team thinking. Teamwork develops in following directions:

- Executive skills training;

- Communication Training;

- Changing the attitude towards teamwork;

- Development of the problem-oriented team;

- Socio-integrative development of the team. 
Usually researches are conducted in a form of a partially standardized interview for team members, and questionnaires that are filled out by a clinic chief executive. The database is formed using multicenter studies; however, in contrast to medical research, the results do not allow to reach strong evidence level due to different systems of training, team's concepts, motivation levels, etc. [38]. This approach is useful for creating effective logistic schemes but lacks unique features of rehabilitation process.

The conception of Shared Mental Models in different modification looks promising due to transition from descriptive to logical-mathematical apparatus [39] [40]. But at the moment this approach is not reproducible in early rehabilitation.

At the same time, in some clinics, this model is embodied in practice, most often team building is intuitive as TDT seems to be the most successful for rehabilitation of severe neurologic patients.

\section{Transdisciplinary Team in Early Neurorehabilitation}

\subsection{Methodology}

As stated above, this model requires requires free information flow in the group. According to our experience, the most important approach tool is feedbacks from/to the patient and within the team for quick identification of phenomena and cooperative decision making about the next steps.

Many years ago we formulated main tasks that should be solved by neurorehabilitation TDT [34]: i.e. dynamic search for resource field, selection of the optimal tactics to overcome the patient's problems, mutual learning, and aid in "burnout" syndrome. Beside formal reports in terms of each speciality, TDT discussion ("round" by Karol) includes metaphors and associations for events' interpretation. Leadership may change at mutual discussions; competitive relations and opinions' polarization pushing team changes are appreciated.

Searching for reasons behind a particular event is not so important in patients with severe impairment of consciousness. The understanding comes after the active response to the event. For promoting work with the person you need to get a hold of his existence. The methodology of teamwork in early rehabilitation is virtually absent, despite the fact that tasks for individual team members can be formulated by an intensive care physician or a neurosurgeon (e.g. enabling patient's spontaneous breathing, preventing contractures, restoring swallowing, etc.). Impaired consciousness is used as a criterion for assessing the condition when defining the problem. It makes a significant obstacle for a rehabilitologist, since learning requires the active participation of the patient.

Uncertainty and elusiveness of consciousness is a challenge. What target should the team chose for its joint actions and what is the evidence of its achievement? Let us replace the poorly categorizable concept of "contact" with the meaningful "living movement" proposed by N. Bernstein [41] [42]. These 
movements are intrinsically related to search and orienting to the future. Living movement is the mastery of space and time rather than body movements in space and time.

A team mainly deals with patient's expressions; it can serve both as an instrument to access an impaired consciousness and a non-trivial tool to study this phenomenon. TDT interacts not only with a patient's deficits and resources, but also with phenomena. Hence, it is useful to consider a team as a dynamic system existing in real time, which must continuously adapt to changing tasks and unpredictable perturbations in order to be effective.

If so, it might have basic features of complex system: that is, a set of elements and their properties, which are in dynamic relationship with each other; the whole is greater than the sum of its parts; the system is superior with respect to its elements; all parts and processes of the whole are interdependent and mutually influence each other. The basic doctrine of systems theory: being inside none of agents can understand entirely what is happening at the moment, but related internal processes convert system to a new state.

A "patient-team" system is semi-open self-organizing one (agents may appear and leave aperiodically, environment may change). Sources of variations lie within the system, information exchange should be in a language accessible to the patient. System development may be described with parameters of energy, information and complexity.

Interaction features in early neurorehabilitation are following [43]:

\begin{tabular}{ll}
\hline Patient & Team \\
\hline $\begin{array}{l}\text { Strives to maintain Status Quo and self-isolation. } \\
\text { "Execution of instructions" is an unknown }\end{array}$ & $\begin{array}{l}\text { Proper handling, accession to the } \\
\text { patient always results in getting an answer. } \\
\text { context for patient }\end{array}$ \\
$\begin{array}{l}\text { Relatives may be temporary agents } \\
\text { The complementary relations prevail. }\end{array}$ \\
\hline
\end{tabular}

The work of the transdisciplinary team is a cyclical process (Figure 1).

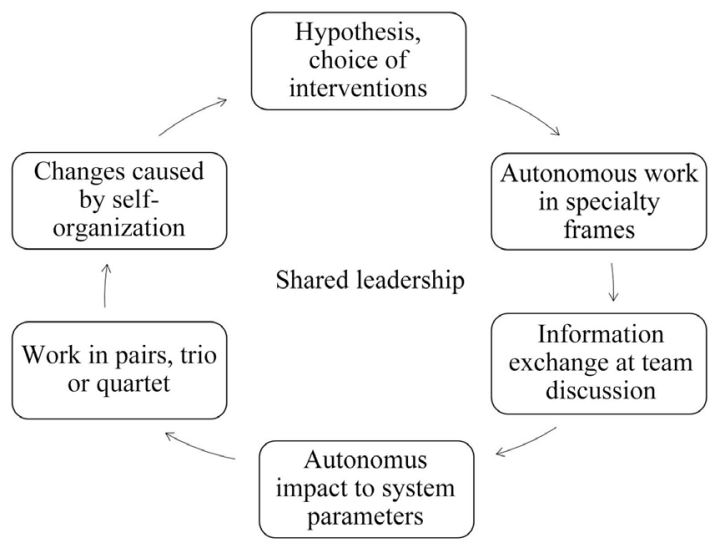

Figure 1 Cycle of teamwork. 
Adjustment of hypotheses and selection of possible modes of operation takes place during discussion. Repeating sessions of specialists, acquisition of information about the current state of a patient, sharing information and hypotheses about what is happening during the rehabilitation process.

Traditionally clinicians consider psychological neurorehabilitation with a patient able to keep verbal communication, yet in TDT psychologist begins to work with a patient being in different states of consciousness coma, vegetative state, mutism, confusion. In deeply altered state of consciousness communication is possible through:

- body expressions, like breath, etc.

- movements, like micro moves of fingers, etc.

- protoemotional expressions, like mimics, simple emotional reactions and feelings, etc.

The proper choice of a signal and nonlinear analysis techniques may significantly alter our understanding of human responses to external and internal stimuli. Our basic assumption is that when studying phenomenon of recovering consciousness, it is necessary to use the same parameters at different levels of the system, taking into account the timescale of a measured process. It is reasonable to consider a team including a patient, or a functioning body (constellation of organs) as non-linear systems. This allows the use of numerous directions of Complex System theory. Currently, you can pick up a set of recording devices to determine functional states of system at different levels using a single set of variables. With proper study design, it is possible to analyze mutual influence of multilevel processes. If time series of any variable are available, it is possible to calculate the following system parameters:

Energy: $E=\Sigma \Delta t_{i} \cdot A_{i}^{2}$, where $A_{i}$ is the signal strength;

Complexity or Stability (e.g. fractal dimension, Hurst index);

Entropy: $H(E)=-\Sigma P_{i} \cdot \log P_{i}$, where $P_{i}$ is the probability of the $I^{\text {th }}$ energy level.

This type of dynamic assessment of a complex system is applicable to different levels of functioning (subsystems), for example, as shown in Figure 2.

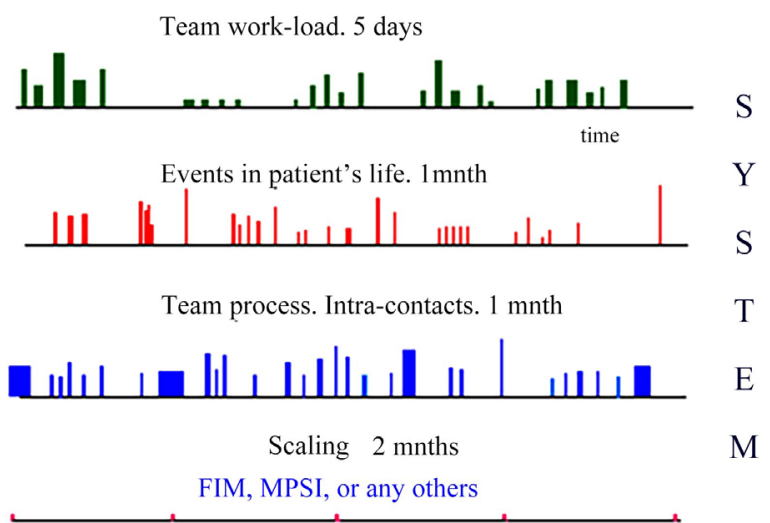

Figure 2. Possible approach to multi-level assessment. 
With time set of any measurable signal, it is possible to quantify system characteristics: energy, entropy, complexity, taking into account the presence of different temporal scales (brain activity, body activity, purposeful acts, behavior, etc.). System parameters are accessible to understanding and qualitative use for participants of rehabilitation process.

This view helps to aware what is happening in Patient-Team cooperation. According our conception we use energy, entropy (information), complexity, describing team-patient dynamic state: team members incorporate it into their vision. Complex system theory has made a significant contribution to the explanation of the characteristics of joint activities and their impact on the result. Synergetics, one of approaches to study of complex systems resulted in development of another direction that offers interpretation of such an important phenomenon as self-organization, that is a process of adjustment of elements belonging to the same level of system by means of internal factors without external specific action (change in external conditions can also have stimulating effect). It results in appearance of a unit having higher quality level. Development of complex system leads to self-organization. We assume self-organization caused by rehabilitation teamwork does play a leading role in emergent signs of consciousness in persons after severe brain damage.

\subsection{Techniques of Teamwork in Neurorehabilitation}

Patients in "vegetative state" or "unresponsive wakefulness" spend a long time in the environment being inaccessible to ideas of others to return their consciousness. For instance, over-ordering is characteristic for patients with deep disturbances of consciousness, yet energy may differ. Team psychologist looks for, amplifies and expand signals, switch its on in connection, being in "dialogue". Working with patients in deeply altered state of consciousness psychotherapeutic approaches based on integral (psychic body) view are most effective. Psychotherapeutic techniques used in work with unconscious patients are rooted in nonlinearity. We use Biosynthesis of D. Boadella [44] and Process-oriented approach of A. Mindell [33]. These approaches are based on principle of feedback (FB); ability to psychosomatic resonance; empathy ("empathic presence", "kinesthetic empathy").

Main techniques are aimed at creating Patient-Psychotherapist system and achieving change. They are:

- "Minimal signals" mostly with patients in coma or vegetative state;

- "Steal the state" if the patient's state is rigid to changes;

- "Grounding" in order to strengthen patient's feelings of base and stability;

- "Centering" for patient's awareness of his emotions and their balance;

- "Facing and Sounding" are used to express feelings, locked by patient before and for his additional self-expression, show up.

Usually rehabilitologists work with patient sequentially. The protocol is strictly defined and patient's workload is 4 or more different sessions per day. Robotics is used widely. Sometimes specialists work in pairs; this is a tool in the early 
period at physical sessions to avoid mechanical overload. If a patient is "stuck" for a long time in the same state of consciousness, joint work of the whole team is carried out. Psychologists usually act as team leaders at these sessions. Other members act as co-therapists. Thereby, the problem of extension of patient's feedbacks is solved.

The following are some examples of the transdisciplinary team-work (Figure 3 ).

Patient I. 2 years after intracerebral hemorrhage, intracerebral hematoma removing, aneurysm clipping, cranioplasty. VS, dependent on artificial ventilation. There were numerous problems TDT faced at different stages of treating. After 3rd surgery the main team task was to enable spontaneous breathing by energy increase and entropy change. Four team participants working together were: ICU physician, neurologist, physiotherapist, and psychologist. The fifth one (team leader "playing coach") was out of frame.

In our opinion, the more static patient's condition is (regardless of deficits' severity), the more diverse should the team be. Different combinations of permanent team members, workspace and types of tasks are used. Team discussions formulate problems for every specialist, and may differ from standard discipline tasks.

Sometimes a specialist, working alone, achieves not only the tasks within the framework of his profession, but also the goal set by the whole team (Figure 4).

Patient L. 3.5 months after severe concomitant TBI. Victim of terroristic

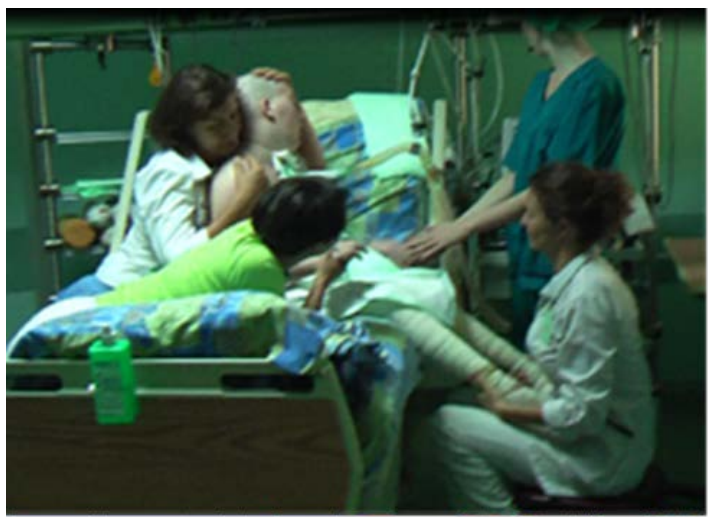

Figure 3. Teamwork with five participants at intensive care unit.

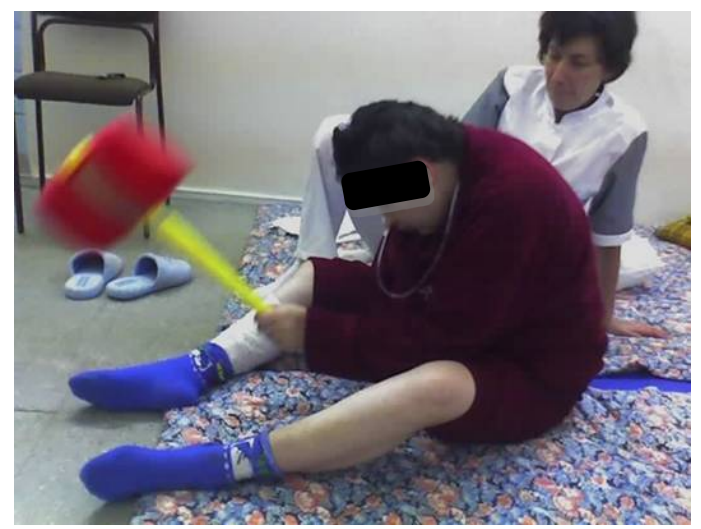

Figure 4. Autonomic physiotherapy session. 
attack. Hyperkinetic mutism (SMC+). The team designated high entropy and energy as the main factors inhibiting patient development. The state of the functional system has changed due to the purposeful expenditure of energy. Tasks for the physiotherapist: to reinforce stereotypic movement, transforming it into meaningful movement, redefining the target (psychological trauma), enriching kinesthesia, postural control improving. Movements in paretic right hand appeared (living movement), forced left body movements stopped as a result.

Shared mental model of the team as a complex system allows achieving a result that is unpredictable, based on a linear causal relationship (as on Figure 5).

Patient D., $3^{\text {rd }}$ month after severe TBI. SMC-. The psychologist and the physiotherapist working together complexificate the system and increase low energy of the patient. Self-organization increases, manifesting not only in "living movement" of the patient, but also in new ideas suggested by the team.

Resistance and stress may arise both in a patient and team members during sessions. The team should change both structurally and functionally according to moment requirements. Directed intervention increases system complexity, leading to changes in energy and entropy. In this case system entropy increases, energy redistributes. Spasticity decreases, leaving room for "living movement".

In addition, the joint work in the session significantly expands the possibilities of monitoring and managing the patient's energy abilities (Figure 6).

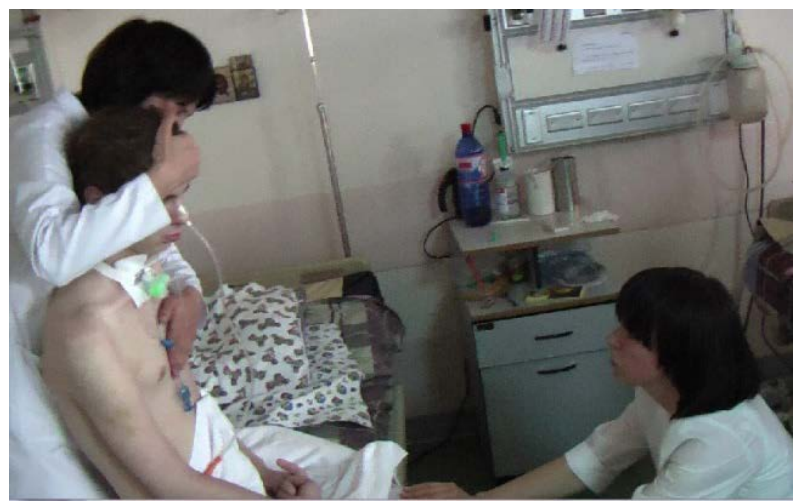

Figure 5. Joint teamwork.

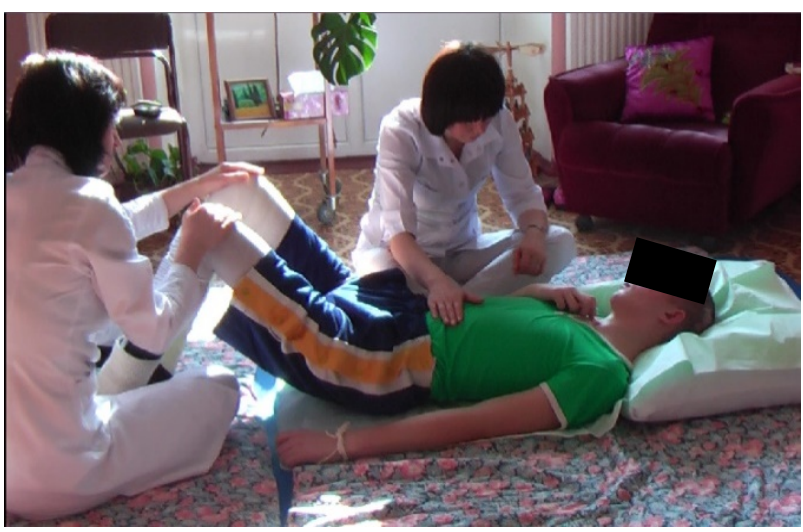

Figure 6. Work in pair aimed at increasing and control of patient's energy. 
Patient N, $4^{\text {th }}$ month after severe TBI. Tetraparesis. Mutism (SMC+) with episodes of "clear consciousness". Psychologist and physiotherapist worked together. The main inhibitory factor was quick exhaustion in all modalities. Energy fell every 7 minutes during the 1rst session. Several sessions increased "clear consciousness" time up to half an hour.

It is also worth mentioning another technique commonly used to teach posture control, namely, stabilographic training. In frames of TDK work, it acquires additional meaning. Postural control training is an important stage in restoration of integrative brain activity in early terms after the severe TBI [45]. We are referring to cases of post-traumatic Korsakov syndrome (posttraumatic amnesia with elements of confusion) according to Russian post-coma classification. Most physicians regard this syndrome as disorder of cognitive functions (reasoning, memory, gnosis, etc.). If it would be any cognitive disorder, then the only treatment would be long training of this one. The reduction of complex phenomenon of altered consciousness to amnestic disorder not only eliminates other cognitive impairment [46], but also closes the way to patient's world. In continuum of consciousness, a demarcation line is drawn arbitrarily, before which there is impaired consciousness, and after only impaired cognition.

Yet we know cases of sudden coming to consciousness. The approach worked up at our clinic under the assumption that post-traumatic Korsakov syndrome is a form of altered consciousness connects these people to reality via grasping emotionally meaningful event or set of events. Co-presence of psychotherapist in the patient's reality transforms the event to here-and-now reality [47].

An additional technique to bring out of this state into clear consciousness is stabilotraining. Posture-controlled patients stuck in this condition for more than 2 weeks began to aware here-and-now reality after 2 - 3 stabilotraining sessions. Given the well-known pattern of accelerated recovery of motor memory and body orientation in space [48], one would expect that in a certain way, designed motor training have an integrating effect on the patient's consciousness [49].

A directional change in system parameters causes appearance of patient involvement. The team identifies these behavioral signs, appropriately processes and returns to the patient.

TDT may begin to work with a patient at early stage, at the same time we have experience working with prolonged unconsciousness. It is usually impossible to determine rehabilitation potential in one examination. Team managed to extend a "dialogue" with the patient in repeating cycles. However, there are problems with long-term quantitative tracking of team processes.

\subsection{Interdisciplinary Research Methods}

A team operates between random and highly ordered states at the critical level (edge of chaos). This allows teams to adapt to both internal and external changes. Effective teamwork is a continuous effort aimed at stabilizing the inherently unstable system [50]. The team shows both stability and flexibility in the "sweet spot" due to supporting co-regulation and adaptive interactions between 
participants.

While neurorehabilitology was studying the team approach as a matter of practice, organizational psychology has made a significant progress in formalization of teamwork in health with input-process-output approach. An increasing number of measuring devices and signal processing allows dealing with sensor-based measurement of team performance [51]. This method would be very fruitful with usage of continuous movement monitoring of each participant and a patient during an autonomous and common work. Then, it would be possible to calculate the system parameters (energy, entropy, complexity).

In parallel, nonlinear methods of quantitative assessment have found increasing application in experimental models of teamwork. These studies allow one to measure processes and their impact on the result. For instance, systemic analysis of motor techniques in sports team members has a high predictive value [52].

Anthropological sciences have adopted nonlinear methods, which enabled evaluation of teamwork (non-technical) skills: Leadership as distributed intellect that plays important role in system self-organization (appearing in "living motion"; Decision-making; Understanding of the situation; Cohesion; Energy management).

Now it is possible to understand change of leadership as well as organization learning based on registration of micro interactions [53]. More complex simulation experiments with telemetric EEG allow associating brain activity features with output of teamwork [53] [54]. On the other hand, measurement of mechanical quasi-oscillations is useful for rehabilitation research, since it allows evaluating the overall change in a system's functional state [55]. Transitional processes of group functional state may show leadership manifesting in problem solving [56].

Some clinical studies use body signals to assess state of consciousness, appealing to higher simplicity and availability of monitoring and taking into account non-linearity [57]. Cardiogram entropy in SMC is a quite reliable correlate of consciousness according to clinical evaluations and generated potentials [58]. This is a convenient system parameter, as entropy change is associated with information.

\section{Conclusions}

An "objective observer" focused on attributes of consciousness such as brain activity, spontaneous and behavioral manifestations "cannot grasp the content of consciousness" [59]. Post-coma states are an example of system self-isolation because of a crushing blow. External support preserves perception-action frame for an indefinite time. A weighted change in actions can cause the patient to "loosen" the frame and "awaken".

Over the past decade, not only the tools and methods of nonlinear analysis have expanded, but also multidisciplinary team has become an object of scientific interest [60]. 
TDT approach outlined in this article leaves boundaries of "objective observation" while maintaining scientific principles. Transdisciplinary rehabilitation team reveals bodily phenomena (being indicative of changing mental condition) through dialogic work with the patient so may become effective tool for consciousness research. Our own 25-year experience as well as experience of colleagues in other countries made it possible to set up the algorithm of early psychological rehabilitation, select special methods, differing of traditional verbal-oriented. To implement and develop communication in absence of speech, TDT has created new semantics with and for every patient.

Work with the patient is carried out individually, in pairs or by several team members, where every participant is a part of a common field, substituting deficit of expressive abilities, making it possible to perception and recognition. Research in the field may use Complex System Theory: it mediates through increasing complexity, maintaining energy, increase and decrease in entropy, and transition from the regularity to margin of chaos. In this way, the "patient-team" system moves to self-organization. This process leads to actualization of consciousness. Qualities of becoming consciousness appear as changes of complex Patient-Team system features. Perhaps brain-damaged patients had not lost their consciousness. Perhaps they do not experience need in it or intention to present it to others. TD team carefully grows intentions and brings back communication experience.

The trans-disciplinary model should become the gold standard for rehabilitation of patients with impaired consciousness. Better understanding could both significantly improve the effectiveness of rehabilitation and elaborate the comprehension of phenomenon.

\section{Conflicts of Interest}

The authors declare no conflicts of interest regarding the publication of this paper.

\section{References}

[1] Cullen, N., Chundalama, J., Bayley, M. and Jutai, J. (2007) The Efficacy of Acquired Brain Injury Rehabilitation. Brain Injury, 21, 113-132.

https://doi.org/10.1080/02699050701201540

[2] Teasell, R., Bayona, N., Marshall, S., et al. (2007) A Systematic Review of the Rehabilitation of Moderate to Severe Acquired Brain Injuries. Brain Injury, 21, 107-112. https://doi.org/10.1080/02699050701201524

[3] Melin, J. (2018) Patient Participation in Physical Medicine and Rehabilitation: A Concept Analysis. International Physical Medicine \& Rehabilitation Journal, 3, 36-42. https://doi.org/10.15406/ipmrj.2018.03.00071

[4] LeDoux, J.E., Michel, M. and Lau, H. (2020) A Little History Goes a Long Way toward Understanding Why We Study Consciousness the Way We Do Today. PNAS, 117, 6976-6984. https://doi.org/10.1073/pnas.1921623117

[5] Nagel, T. (1974). What Is It Like to Be a Bat? The Philosophical Review, 83, 435-450. https://doi.org/10.2307/2183914 
[6] Dennet, D. (1978) Brainstorms: Philosophical Essays on Mind and Psychology. MIT Press, Cambridge.

[7] Searle, J.R. (1992) The Rediscovery of the Mind. MIT Press, Cambridge. https://doi.org/10.7551/mitpress/5834.001.0001

[8] Chalmers, D. (1995) The Conscious Mind: In Search of a Fundamental Theory. Oxford University Press, Oxford.

[9] Chalmers, D.J. (1997) Moving forward to the Problems of Consciousness. Journal of Consciousness Studies, 4, 3-46.

[10] Vasil'ev, V.V. (2010) Challenging Problem of Consciousness and Two Arguments in Favor of Interactionism. (In Russian) http://ecsocman.hse.ru

[11] Hasegawa, H.H., Jamieson, G.A. and Ashkan, K. (2012) Neurosurgery and Consciousness: Historical Sketch and Future Possibilities. Journal of Neurosurgery, 117, 455-462. https://doi.org/10.3171/2012.6.JNS112136

[12] Penrose, R. (1989) The Emperor's New Mind: Concerning Computers, Minds and The Laws of Physics. Oxford University Press, Oxford.

[13] Penrose, R. and Hameroff, S. (2011) Consciousness in the Universe: Neuroscience, Quantum Space-Time Geometry and Orch OR Theory. Journal of Cosmology, 14 1-17.

[14] Tononi, G. (2004) An Information Integration Theory of Consciousness. BMC Neuroscience, 5, 42. https://doi.org/10.1186/1471-2202-5-42

[15] Tononi, G. (2008) Consciousness as Integrated Information: A Provisional Manifesto. Biology Bulletin, 215, 216-242. https://doi.org/10.2307/25470707

[16] Crick, F. and Koch, C. (1998) Consciousness and Neuroscience. Cerebral Cortex, 8, 97-107. https://doi.org/10.1093/cercor/8.2.97

[17] Dennet, D.C. (2005) Sweet Dreams. Philosophical Obstacles to a Science of Consciousness. A Bradford Book, The MIT Press, Cambridge. https://doi.org/10.7551/mitpress/6576.001.0001

[18] Andersen, H.K. (2017) Reductionism in the Biomedical Sciences. In: Solomon, M., Simon, J.R. and Kincaid, H., Eds., The Routledge Companion to Philosophy of Medicine, Routledge, New York, 81-89.

[19] Foucault, M. (1963) The Birth of the Clinic: An Archaeology of Medical Perception. (In Russian)

[20] Giacino, J.T., Ashwal, S. and Childs, N. (2002) The Minimally Conscious State: Definition and Diagnostic Criteria. Neurology, 58, 349-353.

https://doi.org/10.1212/WNL.58.3.349

[21] Wijdicks, E.F.M. and Cranford, R.E. (2005) Clinical Diagnosis of Prolonged States of Impaired Consciousness in Adults. Mayo Clinic Proceedings, 80, 1037-1046. https://doi.org/10.4065/80.8.1037

[22] Laureys, S. and Boly, M. (2012) Unresponsive Wakefulness Syndrome. Archives Italiennes de Biologie, 150, 31-35.

[23] Cairns, H., Oldfield, R.C., Pennybacker, J.B., et al. (1941) Akinetic Mutism with Epidermoid Cyst of the Third Ventricle (with a Report on Associated Disturbance of Brain Potentials). Brain, 64, 273-290.

[24] Dobrokhotova, T.A., Potapov, A.A., Zaytsev, O.S., et al. (1996) Reversible Post-Coma Unconscious States. Sotsial naya i Klinicheskaya Psikhiatriya, 3, 22-25. (In Russian)

[25] Davis, A.E. and Gimenez, A. (2003) Cognitive-Behavioral Recovery in Comatose 
Patients Following Auditory Sensory Stimulation. Journal of Neuroscience Nursing, 35, 202-209. https://doi.org/10.1097/01376517-200308000-00006

[26] Boly, M. and Seth, A.K. (2012) Modes and Models in Disorders of Consciousness Science. Archives Italiennes de Biologie, 150, 172-184.

[27] Casarotto, S., Rosanova, M., Gosseries, O., Boly, M., Massimini, M. and Sarasso, S. (2016) Exploring the Neurophysiological Correlates of Loss and Recovery of Consciousness: Perturbational Complexity. In: Monti, M.M. and Sannita, W.G., Eds., Brain Function and Responsiveness in Disorders of Consciousness, Springer International Publishing, Berlin, 93-104. https://doi.org/10.1007/978-3-319-21425-2 8

[28] Sevdalis, N. (2013) Non-Technical Skills and the Future of Teamwork in Healthcare Settings. The Health Foundation.

https://psnet.ahrq.gov/issue/non-technical-skills-and-future-teamwork-healthcare-s ettings

[29] Winson, R., Wilson, B.A. and Bateman, A. (2017) The Brain Injury Rehabilitation Workbook. Guilford Press, New York.

https://www.guilford.com/books/The-Brain-Injury-Rehabilitation-Workbook/Wins on-Wilson-Bateman/9781462528509

[30] Baker, D.P., Gustafson, S., Beaubien, J., Salas, E. and Barach, P. (2005) Medical Teamwork and Patient Safety: The Evidence-Based Relation. AHRQ Pub. No. 05-0053, April 2005. Agency for Healthcare Research and Quality, Rockville. http://www.ahrq.gov/qual/medteam

[31] Gorman, J.C., Amazeen, P.G. and Cooke, N.J. (2012) Team Coordination Dynamics. Nonlinear Dynamics, Psychology, and Life Sciences, 14, 265-289.

[32] Shapiro, B.Yu. (2002) Principles of Interdisciplinary Team Work. In: Firsov, M.V. and Shapiro, B.Yu., Eds., Psychology of Social Work. The Content and Methods of Psychosocial Practice, Akademiya, Moscow, 35-68. (In Russian)

[33] Mindell, A. (1989) COMA: Key to Awakening. Shambhala Publications Inc., Boulder.

[34] Naydin, V., Maksakova, O., Krotkova, O. and Smirnova, N. (2002) Neurorehabilitation after Brain Injury. In: Clinical Guidelines for Head Injury, Vol. 3, Antidor, Moscow, 516-542.

[35] Hilleboe, H.E. (1964) Teamwork in Rehabilitation-From Fancy to Fact. American Journal of Public Health and the Nation's Health, 54, 751-757.

https://doi.org/10.2105/AJPH.54.5.751

[36] Körner, M., Wirtz, M.A., Bengel, J. and Göritz, A.S. (2015) Relationship of Organizational Culture, Teamwork and Job Satisfaction in Interprofessional Teams. BMC Health Services Research, 15, 243. https://doi.org/10.1186/s12913-015-0888-y

[37] Karol, R.L. (2014) Team Models in Neurorehabilitation: Structure, Function, and Culture Change. NeuroRehabilitation, 34, 655-669. https://doi.org/10.3233/NRE-141080

[38] Suddick, K.M. and De Souza, L. (2006) Therapists' Experiences and Perceptions of Teamwork in Neurological Rehabilitation: Reasoning behind the Team Approach, Structure and Composition of the Team and Team-Working Processes. Physiotherapy Research International, 11, 72-83. https://doi.org/10.1002/pri.325

[39] Mathieu, J.E., Goodwin, G.F., Heffner Tonia, S., Eduardo, S. and Cannon-Bowers, J.A. (2000) The Influence of Shared Mental Models on Team Process and Performance. Journal of Applied Psychology, 85, 273-283. https://doi.org/10.1037/0021-9010.85.2.273

[40] Shanahan, C., Best, C., Finch, M. and Sutton, C. (2007) Measurement of the Beha- 
vioral, Cognitive, and Motivational Factors Underlying Team Performance. Air Operational Division, Commonwealth of Australia.

[41] Bernshtein, N.A. (2008) Biomechanics and Physiology of Movements. Selected Psychological Works. 3rd Edition, MPSI. (In Russian)

[42] Bernstein, N.A. (1967) The Co-Ordination and Regulation of Movements. Pergamon Press, Oxford.

[43] Maksakova, O. (2014) Teamwork as a Way to Recovery of Consciousness. Vopr. Neurochir. 1. http://www.mediasphera.ru/journals/burdenko

[44] Boadella, D. (2015) Life Streams. An Introduction to Biosynthesis. Routledge, Abingdon-on-Thames!' https://doi.org/10.4324/9781315737713

[45] Zhavoronkova, L.A., Zharikova, A.V. and Maksakova, O.A. (2010) Integrating Role of Voluntary Postural Control Recovery during Rehabilitation of Patients with Traumatic Brain Injury. Zh Vyssh Nerv Deiat I P Pavlova, 60, 678-688. (In Russian)

[46] Wilson, B.A., Evans, J.J., Emslie, H., Balleny, H., Watson, P.C. and Baddeley, A.D. (1999) Measuring Recovery from Post-Traumatic Amnesia. Brain Injury, 13, 505-520. https://doi.org/10.1080/026990599121412

[47] Maksakov, V. and Urakov, S. (2003) Psychologist in a Neurosurgical Clinic: Work with Korsakov's Syndrome. Moscow Psychotherapeutic Journal, No. 2, 106-113. (In Russian)

[48] Nott, M.T., Chapparo, C. and Heard, R. (2008) Effective Occupational Therapy Intervention with Adults Demonstrating Agitation during Post-Traumatic Amnesia. Brain Injury, 22, 669-683. https://doi.org/10.1080/02699050802227170

[49] Zhavoronkova, L.A., Maksakova, O.A., Zharikova, A.V., Flerov, I.S., Shchekut'ev, G.A. and Naidin, V.L. (2009) EEG Markers of the Stabilotraining Effect during the Rehabilitation of Patients with Posttraumatic Korsakoff's Syndrome. Human Physiology, 35, 142-151. https://doi.org/10.1134/S0362119709020029

[50] Rosen, M.A., Dietz, A.S., Yang, T., Priebe, C.E. and Pronovost, P.J. (2015) An Integrative Framework for Sensor-Based Measurement of Teamwork in Healthcare. Journal of the American Medical Informatics Association, 22, 11-18.

[51] Correa, U.C., Alegre, F.A.M., Freudenheime, A.M., et al. (2012) The Game of Futsal as an Adaptive Process. Nonlinear Dynamics, Psychology, and Life Sciences, 16, 185-204.

[52] Hazy, J.K. and Silberstang, J. (2009) Leadership within Emergent Events in Complex Systems: Micro-Enactments and the Mechanisms of Organizational Learning and Change. International Journal of Learning and Change, 3, 230-247.

https://doi.org/10.1504/IJLC.2009.024690

[53] Stevens, R.H., Galloway, T.L., Wang, P., et al. (2012) Cognitive Neurophysiologic Synchronies: What Can They Contribute to the Study of Teamwork? Human Factors, 54, 489-502. https://doi.org/10.1177/0018720811427296

[54] Stevens, R., Gorman, J.C., Amazeen, P., Likens, A. and Galloway, T. (2013) The Organizational Neurodynamics of Teams. Nonlinear Dynamics, Psychology, and Life Sciences, 17, 67-86.

[55] Maksakova, O.A. and Lukianov, V.A. (2008) Kinetographic Assessment of the Functional State of Healthy Humans: A Pilot Study. Fiziologiya Cheloveka, 34, 178-187. https://doi.org/10.1134/S0362119708020047

[56] Lukyanov, V.I., Maksakova, O.A., Menshikov, I.S., Menshikova, O.R., Senko, O.V. and Chaban, A.N. (2012) Functional State and Efficiency of Participants in Laboratory Markets. Theory and Control Systems, 6, 202-219. 
[57] Wieser, M., Buetler, L. and Vallery, H. (2012) Quantification of Clinical Scores through Physiological Recordings in Low-Responsive Patients: A Feasibility Study. Journal of NeuroEngineering and Rehabilitation, 9, Article No. 30.

http://www.jneuroengrehab.com/content/9/1/30 https://doi.org/10.1186/1743-0003-9-30

[58] Gosseries, O., Schnakers, C., Ledoux, D., et al. (2011) Automated EEG Entropy Measurements in Coma, Vegetative State/Unresponsive Wakefulness Syndrome and Minimally Conscious State. Functional Neurology, 36, 25-30.

[59] Metzinger, Th. (2000) Neural Correlates of Consciousness-Empirical and Conceptual Questions. MIT Press, Cambridge, 43.

https://doi.org/10.7551/mitpress/4928.001.0001

[60] Korb, W., Geißler, N. and Strauß, G. (2015) Solving Challenges in Inter- and Trans-Disciplinary Working Teams: Lessons from the Surgical Technology Field. Artificial Intelligence in Medicine, 63, 209-219.

https://doi.org/10.1016/j.artmed.2015.02.001 